\title{
The analysis of European lacquer: optimization of thermochemolysis temperature of natural resins
}

\author{
Louise Decq $^{1,2}$, Frederic Lynen ${ }^{2}$, Michael Schilling ${ }^{3}$, Wim Fremout ${ }^{1}$, Vincent \\ Cattersel $^{4}$, Delphine Steyaert ${ }^{5}$, Charles Indekeu ${ }^{4}$, Emile Van Binnebeke ${ }^{5}$ and \\ Steven Saverwyns ${ }^{1}$
}

1 Royal Institute for Cultural Heritage (KIK-IRPA), Department Laboratories, Jubelpark 1, 1000 Brussels (Belgium).

2 Ghent University, Department of Organic and Macromolecular Chemistry, Krijgslaan 281, 9000 Ghent (Belgium).

3 Getty Conservation Institute, 1200 Getty Center Drive, Suite 700, Los Angeles, CA 90049-1684 (USA).

4 University of Antwerp, Conservation Studies - Heritage \& Sustainability, Blindestraat 9, 2000 Antwerp (Belgium).

5 Royal Museums of Art and History (RMAH), Jubelpark 10, 1000 Brussels (Belgium)

* Corresponding author's email address, phone: louise.decq@kikirpa.be / steven.saverwyns@kikirpa.be, +32-2-7396711

Keywords: European lacquer; THM-GC/MS; temperature optimisation; thermochemolysis; AMDIS; sandarac; mastic; colophony; Congo copal, pyrolysis with on-line methylation

\section{Acknowledgments}

The authors would like to express their deep appreciation to Jonas Veenhoven (University of Antwerp, Antwerp, Belgium) and Henk van Keulen (Rijksdienst Cultureel Erfgoed, Amsterdam, the Netherlands) for the interesting discussions and insights on this research. The authors would like to express their gratitude to Hans Beeckman (Royal Museum for Middle Africa - KMMA, Tervuren, Belgium), Viviane Leyman (Botanic Garden Meise, Meise, Belgium), Annegret Fuhrman (Hochschule für Bildende Künste, Dresden, Germany) for providing us with natural resins from their collections. The authors appreciate the statistical support of Jonas Tundo, data analyst at Artycs, Brussels. The research leading to these results has been subsidized by the Belgian Science Policy through the contract no. BR/121/A3/ELINC within the BRAIN project "European Lacquer in Context" (ELinC).

\begin{abstract}
In order to optimize chromatographic analysis of European lacquer, thermochemolysis temperature was evaluated for the analysis of natural resins. Five main ingredients of lacquer were studied: sandarac, mastic, colophony, Manila copal and Congo copal. For each, five temperature programs were tested: four fixed temperatures $\left(350^{\circ} \mathrm{C}, 480^{\circ} \mathrm{C}, 550^{\circ} \mathrm{C}, 650^{\circ} \mathrm{C}\right)$ and one ultrafast thermal desorption (UFD), in which the temperature rises from 350 to $660^{\circ} \mathrm{C}$ in one minute. In total, integrated signal of 27 molecules partially characterizing the five resins were monitored to compare the different methods. A compromise between detection of compounds released at low temperatures and compounds formed at high temperatures was searched. $650^{\circ} \mathrm{C}$ is too high for both groups, $350^{\circ} \mathrm{C}$ showed best for the first, $550^{\circ} \mathrm{C}$ for the second. Fixed temperatures of $480^{\circ} \mathrm{C}$ or UFD proved to show the best consensus in order to detect most marker molecules. UFD was slightly better for the molecules released at low temperatures, while $480^{\circ} \mathrm{C}$ showed best compounds formed at high temperatures.
\end{abstract}




\section{Introduction}

Oriental lacquers are natural polymers produced from the exudates of three species from the Anacardiaceae family growing in different regions of Asia[1-3]. They are the object of a tradition of thousands of years of craftsmanship, admired for their durability and gloss. With the rise of overseas trade in the $17^{\text {th }}$ century, oriental lacquerware arrives on a more regular basis in Europe. It was scares, valuable and not well understood, but the impact of its arrival was considerable and long-lasting: loved for their exclusivity and beauty, these glossy luxury objects came into vogue and brought a new, exotic taste to the Old World [4]. Soon, local production of furniture and small objects was inspired by the success of imported oriental lacquer. Lacking the raw materials and the technology of the East, European craftsman imitated Asian lacquer using their own skills and materials familiar to them. The flourishing worldwide trade brought them a wide range of possible ingredients to choose from, including mastic, sandarac, shellac, amber, copals, gum elemi and benzoin. It is remarkable how close the imitation's surfaces can resemble their oriental examples. A new tradition was born.

European lacquers, are complex, multi-layered coatings, mainly composed of various natural resins. Depending on the recipes, oils, gums, pigments and other ingredients can be added. Unlike Asian lacquer, different resins were usually combined to achieve the best coating properties, such as gloss, color, applicability, hardness and flexibility[5,6]. Hard resins such as copal and sandarac could for example be mixed with gum elemi as plasticizer[6]. If resins in themself are diverse in constitution, European lacquers are even more. A wide range of different molecules is expected to be present, including terpenoids, fatty acids, alcohols and hydrocarbons. Moreover, the polylabdanoid matrix in many of them as well as compositional evolution during preparation and aging can make them hard to dissolve in standard solvents, making the analysis of European lacquer challenging.

In order to know more about the technology and ingredients used, subsequent lacquer layers have to be sampled and analyzed separately, at the same time minimizing the damage to the object. This results in many samples of very limited size. For these small samples of diverse constitution, thermochemolysis gas chromatography-mass spectrometry, also called thermally assisted hydrolysis and methylation gas chromatography-mass spectrometry (THM-GC/MS), was chosen as principle technique, efficiently returning a maximum of information on the different ingredients with the use of only very limited sample amount. ThermochemolysisGC/MS is today one of the most important techniques to analyze resinous materials in general [7-19], and it is a powerful method to analyze European lacquer as well $[20,21]$.

Prior to gas chromatography, thermochemolysis reduces the sample to less polar, alkylated and smaller molecular weight products. Since the introduction of pyrolysis GC-MS with in situ derivatisation, tetramethyl ammonium hydroxide (TMAH) has been the preferred alkylation reagent for the analysis of modern natural resins [13]. Methylation of acidic and hydroxylic groups in combination with transesterification of esters and cleavage reactions can take place $[19,22]$. Thermochemolysis has been applied in many set-ups, with different alkylation reagents and at different 
temperatures; all three factors may have important influence on the cleavage and methylation obtained. The choice for TMAH during this project has been motivated by the maximal interchange of results and findings with other institutes.

When optimizing the thermochemolysis for European lacquer ingredients, it is the aim to obtain chromatograms that are most characteristic for the compounds present, so that most can be known about how the lacquer was made. Molecules have to be cleaved and methylated to enable analysis, but more extensive fragmentation or modification hamper the interpretation and are therefore to be avoided. Unwanted side reactions, including isomerization, elimination and nitrogen incorporation, have been frequently observed in thermochemolysis with TMAH as alkylation reagent [14,19,23-29], with solvent type, excess of TMAH and temperature being identified as influencing factors. Water as solvent for the TMAH is suggested to perform better than methanol but limited solubility of resins and a long drying time are important counter arguments $[26,27,30]$. Excess of TMAH favors side reactions by increasing both alkalinity and availability of reactive nitrogen groups in the reaction[26-28]. Most clearly, however, high thermochemolysis temperature has been proven to enhance the occurrence of unwanted side products $[14,19,25,26]$.

Therefore, a main focus point in the method optimization for European lacquer was the choice of the temperature program to be used for hydrolysis and methylation of the resin sample in presence of TMAH. For resinous materials in general, an optimized temperature is not agreed upon. Temperatures of $600-650^{\circ} \mathrm{C}$ or higher have been reported frequently [9-12,17,31,24,32,33]. Also a double shot method combining a lower temperature thermal desorption at 250 or $300{ }^{\circ} \mathrm{C}$, followed by high temperature pyrolysis $\left(600\right.$ or $\left.610^{\circ} \mathrm{C}\right)$ has been used successfully by some authors [7,18,34]; $550^{\circ} \mathrm{C}$ is also applied for varnish and lacquer analysis[3,8,35]. For the study of amber, thermochemolysis temperatures up to $650^{\circ} \mathrm{C}$ are applied [17,36], but after optimization study by Anderson[14], $480^{\circ} \mathrm{C}$ is frequently preferred, sometimes completed with an additional analysis at $300^{\circ} \mathrm{C}$ to show occluded compounds only $[13,15,16,37,38]$. Steadily increasing temperatures have been used rarely $\left(200-700^{\circ} \mathrm{C}\right)$ [21].

With this test, an optimal thermochemolysis temperature is searched for five terpenoid natural resins, all important ingredients in the production of $17^{\text {th }}, 18^{\text {th }}$ and $19^{\text {th }}$ Century European lacquer: sandarac, mastic, colophony, Manila copal and Congo copal. While terpenoids exhibit enormous structural diversity and chemical complexity, they are all united by a common biosynthetic origin [39]. They again can be subdivided into mono-, sesqui-, di- and triterpenes, depending on the number of five carbon building blocks (isopentenyl diphosphate and dimethylallyl diphosphate) which were involved during biosynthesis. Mono- and sesquiterpenes are usually volatile [39]. They can have important influence during the production and application of the lacquer, but, due to their volatile nature and polymerisation, they are unlikely to survive aging in detectable amounts [12]. Therefore, in this study focus is given to the detection of diterpenes (as present in sandarac, colophony, Manila copal and Congo copal) and triterpenes (as present in mastic) and their polymers.

The five selected resins were analyzed at 5 different temperature programs. For four programs a fixed oven temperature was chosen: $350,480,550$ and $650^{\circ} \mathrm{C}$. The fifth program, called ultrafast thermal desorption (UFD) consisted of a rising 
temperature, climbing from $350^{\circ} \mathrm{C}$ to $660^{\circ} \mathrm{C}$ in one minute. Each resin-temperature combination was repeated three times.

\section{Materials and techniques}

\subsection{Analytical reagents and reference materials}

The reagents used to prepare samples and facilitate hydrolysis and methylation were tetramethylammonium hydroxide $25 \mathrm{wt} . \%$ in methanol (Sigma Aldrich) and absolute methanol for HPLC analysis (Acros organics, 99.99\%). Retention index calibration was performed using Supelco C7-C30 saturated alkanes standard $(1000 \mu \mathrm{g} / \mathrm{ml}$ in hexane).

Since contamination and misidentification easily happen with resins $[12,40-45]$ resin samples from historical, non-commercial origin were chosen. All five have been harvested at least 100 years ago, and unavoidably underwent natural aging during their long storage. The sandarac and mastic samples date from the $18^{\text {th }}$ century, conserved in the well-studied Vigani's cabinet in Cambridge Queens' College (resp. resins "Sandaracha" A/26 and "Mastiche" A/11 [46,47]). The colophony and Manila copal were provided by Botanic Garden Meise (resp. "Pinus taeda L." BR-CBC02205 originally from the collection of Ambroise Delacre, pharmacist at Brussels, ca. 1880 and "Resina Copal Manilla" BR-CBC01525, originally from the collection of Carl von Martius (1794-1868)); Congo copal was provided by the Royal Museum for Middle Africa in Tervuren ("Copaifera demeusei" 202 100/30).

\subsection{Preparation of samples for thermochemolysis-GC/MS}

Several grains of each sample were ground, and a small amount of 200-400 $\mu \mathrm{g}$ was transferred to a glass vial. $80-160 \mu \mathrm{l} 2.5 \mathrm{wt} \%$ TMAH in methanol solution was added, relative to the weight of the sample. This solution also contained $100 \mathrm{ng} / \mu \mathrm{l}$ heptadecanoic acid and 5ng/ $\mu \mathrm{l}$ anthracene in solution, both as internal standard. The content of the vial was well mixed to homogenize, and $2 \mu 1$ was transferred to the stainless steel pyrolysis cup (Frontier Lab Eco-cup LF) with auto-Rx glass fiber disc. For the fixed temperatures, the cup was pyrolyzed at given temperatures for 0.2 minutes, and left in the oven when chromatographical analysis started. For ultrafast desorption, the cup was heated during one minute, and ejected a few seconds later, before chromatographical analysis was started.

Efforts were taken to minimize the time span between preparation of the mixture with TMAH and the last analysis of the resin. The series of five temperatures for a resin were repeated two times, adding up to 15 analyses per resin. It resulted in a time span of 19 hours on average.

\subsection{Instrumentation on-line thermochemolysis-GC/MS}


Thermochemolysis was carried out in a Frontier Lab Multi-Shot Pyrolyzer (3030D), in a helium atmosphere, fed with an autoshot sampler AS-1020ET. The interface and the injector of the chromatographic system were kept at $300^{\circ} \mathrm{C}$, but the analytical column was directly coupled to the pyrolyzer via a custom made split device (split ratio 20), minimizing dead volume and improving the signal ${ }^{1}$. For the chromatographic separations, a TraceGC gas chromatograph (Thermo), hyphenated with a PolarisQ Ion Trap mass spectrometer (Thermo), was used. Separations were accomplished on a SLB-5ms capillary column (Supelco, $20 \mathrm{~m}$ x $0.18 \mathrm{~mm}$ i.d. x $0.18 \mu \mathrm{m}$ film thickness) applying following temperature program: initially the oven temperature was maintained at $35^{\circ} \mathrm{C}$ for $1 \mathrm{~min}$ after pyrolysis. Next, a $10^{\circ} \mathrm{C} / \mathrm{min}$ gradient was applied until $240^{\circ} \mathrm{C}$; finally the column was heated to a temperature of $315^{\circ} \mathrm{C}$ at a rate of $6^{\circ} \mathrm{C} / \mathrm{min}$; this temperature was maintained during $5 \mathrm{~min}$. Carrier gas was helium at a constant flow of $0.9 \mathrm{~mL} / \mathrm{min}$. The MS transfer line temperature was kept at $290^{\circ} \mathrm{C}$. Ionization was carried out in the ion volume of the ion trap mass spectrometer under the standard EI positive mode at $70 \mathrm{eV}$. The mass spectrometer was scanned in the 35-650 amu range, with a cycle time of $0.59 \mathrm{~s}$.

\subsection{Data treatment of pyrograms}

Integrated signal of selected markers in the pyrograms was calculated with the AMDIS software (Automated Mass spectral Deconvolution and Identification System,v.2.70). AMDIS computes the integrated signal value as the area under the component after deconvolution[48]; This calculation avoids signal from background and adjacent peaks. The chromatograms were not normalized. Kováts retention indices were calculated by AMDIS, based on the separation of a C7-C30 alkanes mixture. Therefore, retention indices higher than 3000 could not be determined. Mass spectral identification was performed using the NIST 11 Mass Spectral Library, using spectra provided by other institutions (via shared libraries of RAdICAL/ESCAPE and Users' Group for Mass Spectrometry and Chromatography MaSC) and published reference data.

\section{Results and discussion}

Molecules produced during thermochemolysis depend on the compounds present in the sample and their relation to the polymeric network or matrix. Some will be released at low temperatures; others are only formed at high temperatures, or may be destroyed or altered at higher temperatures. Therefore, it is expected that marker compounds react differently on different temperature programs.

For each resin, a set of peaks was selected to compare their integrated signal through the different temperature programs. Table 1 summarizes the total of 27 molecules selected, most of them were (partially) known markers [4,7$9,24,41,44,46,49]$, one is an unidentified peak that appears when Congo copal is submitted to high temperature; it was selected for this characteristic. A THM-GC/MS chromatogram of each resin at $480^{\circ} \mathrm{C}$ is given in figure 1 , with the position of markers

\footnotetext{
${ }^{1}$ Kindly provided by Henk van Keulen, Rijksdienst Cultureel Erfgoed (RCE), Amsterdam, the Netherlands
} 
followed indicated. The mean and standard deviation of three measurements for all selected molecules are visualized in figure $2^{2}$.

Some fragments formed during pyrolysis, are not characteristic for only one resin. Both sandarac and Manila copal contain a polycommunic acid polymer, and this familiarity results in some common peaks $[7,9,18,24,44]$. However, being trapped in a structure that is chemically not identical, their properties regarding pyrolysis temperature may differ. Therefore, polycommunic acid markers "b1" and "b4" (named by Van den Berg [18], with structures suggested there; polycommunic acid pyrolysates extensively studied in amber class 1 [15,38,50]; markers nr. 1, 2, 18, 19) are followed separately for both resins.

Table 1. Overview of resin samples used and the markers selected of each. Retention index (completed with published values by van Keulen) and retention time are given, as well as main molecular fragmentation.

\begin{tabular}{|c|c|c|c|c|c|}
\hline $\begin{array}{l}\text { Resin } \\
\text { (current } \\
\text { plant name) }\end{array}$ & $\begin{array}{l}\text { Marker } \\
\text { number }\end{array}$ & Markers & $\begin{array}{l}\text { Retention } \\
\text { Index } \\
\text { (retention } \\
\text { time) }\end{array}$ & $\begin{array}{l}\text { Retention } \\
\text { Index } \\
\text { (Van } \\
\text { Keulen } \\
2015[8] \text { ) }\end{array}$ & $\begin{array}{l}\text { Characteristic EI } \\
\text { fragment ions } \\
(\mathbf{m} / \mathbf{z})\end{array}$ \\
\hline $\begin{array}{l}\text { Sandarac } \\
\text { (Tetraclinis } \\
\text { articulata } \\
\text { (Vahl) } \\
\text { Mast.) }\end{array}$ & $\begin{array}{l}1 \\
2 \\
3 \\
4 \\
5 \\
6 \\
7\end{array}$ & $\begin{array}{l}\text { Poly communic marker b1 } \\
\text { Poly communic marker b4 } \\
\text { Ferruginol methoxy } \\
\text { Trans-communic acid methyl ester } \\
\text { Sandaracopimaric acid methyl ester } \\
\text { Methyl-hydroxy sandaracopimaric acid } \\
\text { Sandaracopimaric acid, } 12 \text { acetoxy }\end{array}$ & $\begin{array}{l}1601(14.52) \\
1758(16.29) \\
2239(20.93) \\
2257(21.09) \\
2265(21.15) \\
2413(22.45) \\
2511(23.3)\end{array}$ & $\begin{array}{l}1614 \\
1774 \\
2246 \\
- \\
2300 \\
2414 \\
2507\end{array}$ & $\begin{array}{l}161-177-236 \\
173-188-248 \\
189-285-300 \\
105-121-241-316 \\
121-181-257-316 \\
121-346 \\
121-299-314\end{array}$ \\
\hline $\begin{array}{l}\text { Mastic } \\
\text { (Pistacia } \\
\text { lentiscus L.) }\end{array}$ & $\begin{array}{l}8 \\
9 \\
10 \\
11 \\
\end{array}$ & $\begin{array}{l}\text { Mastic compound } 5 \\
\text { Mastic component } \\
\text { Moronic acid ME } \\
\text { Oleanolic acid ME }\end{array}$ & $\begin{array}{l}-(32.04) \\
-(32.27) \\
-(32.96) \\
-(33.17) \\
\end{array}$ & $\begin{array}{l}- \\
- \\
3505 \\
3588 \\
\end{array}$ & $\begin{array}{l}219 \\
203-219-262 \\
189-249-468 \\
203-262-468 \\
\end{array}$ \\
\hline $\begin{array}{l}\text { Colophony } \\
\text { (Pinus taeda } \\
\text { L.) }\end{array}$ & $\begin{array}{l}12 \\
13 \\
14 \\
15 \\
16\end{array}$ & $\begin{array}{l}\text { Pimaric acid ME } \\
\text { Isopimaric acid ME } \\
\text { Abietic acid ME } \\
\text { Tetradehydroabietic acid } 7 \text { methoxy ME } \\
\text { Methyl } \quad \text { 12-methoxyabieta8,11,13-trien- } \\
\text { 20oate }\end{array}$ & $\begin{array}{l}2244(20.97) \\
2307(21.53) \\
2397(22.31) \\
2451(22.79) \\
2488(23.13)\end{array}$ & $\begin{array}{l}- \\
- \\
- \\
- \\
-\end{array}$ & $\begin{array}{l}121-257-316 \\
241-257-316 \\
241-256-316 \\
227-267-342 \\
269-344\end{array}$ \\
\hline $\begin{array}{l}\text { Manila } \\
\text { copal } \\
\text { (Agathis } \\
\text { dammara } \\
\text { (Lamb.) } \\
\text { Rich. \& } \\
\text { A.Rich.) } \\
\end{array}$ & $\begin{array}{l}17 \\
18 \\
19 \\
20 \\
21 \\
22\end{array}$ & $\begin{array}{l}\text { Marker } 4 \\
\text { Poly communic marker b1 } \\
\text { Poly communic marker b4 } \\
\text { 16.17-bisnordehydroabietic acid ME } \\
\text { Agathic acid isomer DME1 } \\
\text { Agathic acid isomer DME2 }\end{array}$ & $\begin{array}{l}1593(14.44) \\
1598(14.50) \\
1756(16.26) \\
2163(20.26) \\
2445(22.74) \\
2498(23.21)\end{array}$ & $\begin{array}{l}- \\
1614 \\
1774 \\
- \\
- \\
-\end{array}$ & $\begin{array}{l}145-160-188-220 \\
161-177-236 \\
173-188-248 \\
211-271 \\
189 \\
121-175-201-288\end{array}$ \\
\hline $\begin{array}{l}\text { Congo copal } \\
\text { (Guibourtia } \\
\text { demeusei } \\
\text { (Harms) } \\
\text { J.Leonard) }\end{array}$ & $\begin{array}{l}23 \\
24 \\
25 \\
26 \\
27\end{array}$ & $\begin{array}{l}\text { Poly ozic marker C1 } \\
\text { Poly ozic marker C2 } \\
\text { Copal unknown } \\
\text { copalic/entcopalic acid } \\
\text { "copal 11" }\end{array}$ & $\begin{array}{l}1637(14.93) \\
1733(16.01) \\
2141(20.04) \\
2315(21.56) \\
2395(22.26)\end{array}$ & $\begin{array}{l}1678 \\
- \\
- \\
2330 \\
-\end{array}$ & $\begin{array}{l}161-177-236 \\
173-189-248 \\
107-177-305 \\
81-244-303 \\
223-305-318\end{array}$ \\
\hline
\end{tabular}

\footnotetext{
${ }^{2}$ Due to one failed analysis, only two measurements for the combination $480^{\circ} \mathrm{C}$ - mastic could be used.
} 


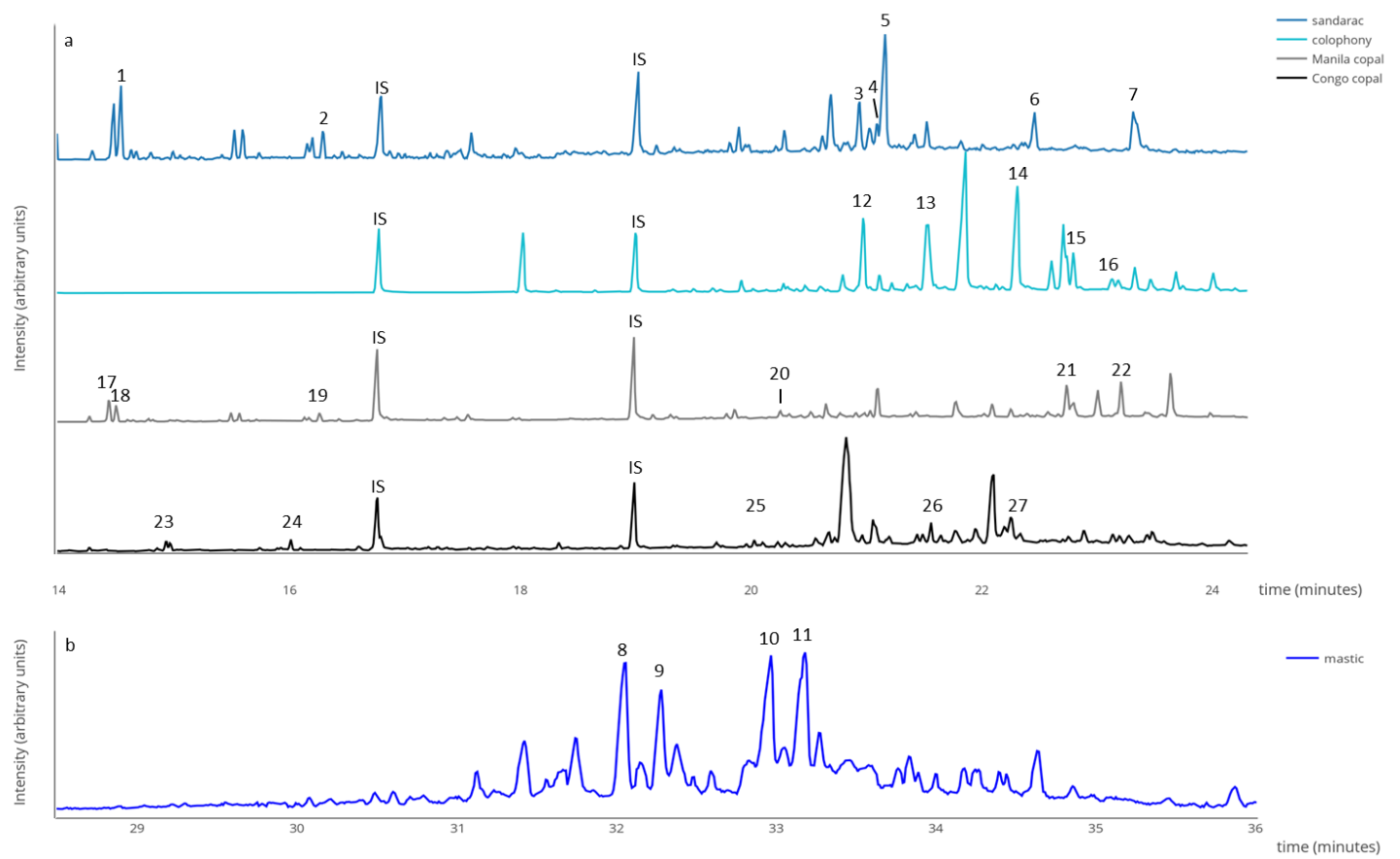

Figure 1 Total Ion Count (TIC) of gas chromatogram of sandarac, colophony, Manila copal and Congo copal (a; diterpenoid region) and mastic (b; triterpenoid region), pyrolyzed at $480^{\circ} \mathrm{C}$. Selected markers are indicated. 


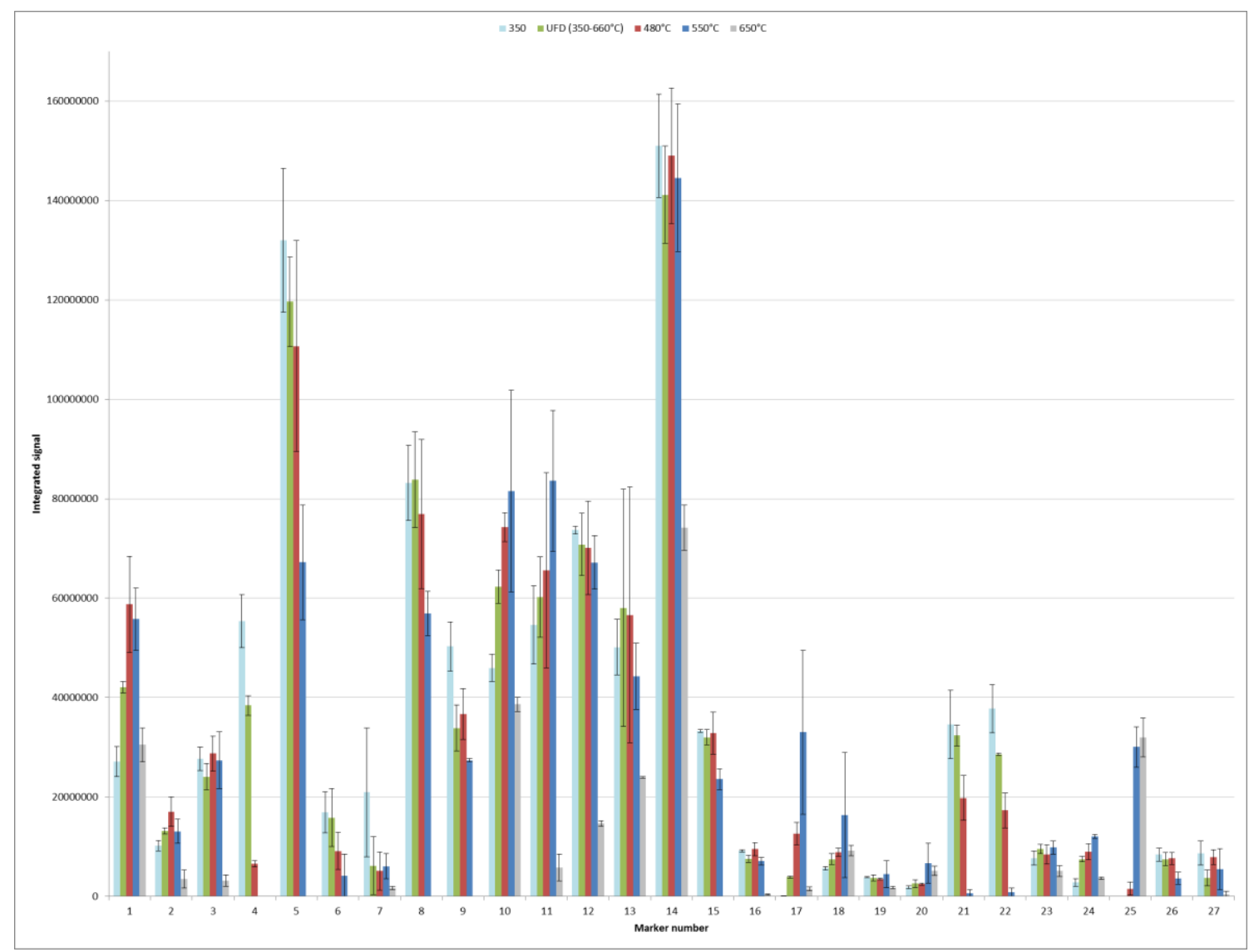

Figure 2. Mean and standard deviation of integrated signal of selected markers. Marker numbers are specified in Table 1. Based on their behaviour, markers can be divided in three groups, indicated with $\circ$, * and + (discussion below).

In the ultrafast thermal desorption (UFD) heating program, the sample falls into the oven at $350^{\circ} \mathrm{C}$, and is consequently heated to $660^{\circ} \mathrm{C}$ within one minute. The idea of this method is that easily volatilized compounds can escape and condense on the cool column before possibly being destroyed at high temperatures. When temperatures rise, more compounds are set free and gathered on the column. It was therefore expected, in theory, that this temperature program should be the best compromise between a fixed low or high temperature, as a possible alternative for double shot analysis. Double shot analysis, a low temperature thermal desorption followed by high temperature pyrolysis on the same sample, has the advantage over single shot analysis that easily volatilized compounds and compounds formed at high temperatures are both detected, and clear distinction is made between them. Moreover, degradation products of compounds released at low temperatures are avoided. Major drawback of this method is that TMAH, volatilized in the first step, is likely to be absent in the second - if not added manually again. This makes the procedure more time consuming and not compatible with an autosampler. Recovering the cup and manually adding TMAH also bears the risk of losing the sample.

From the results, it is clear that pyrolysis at fixed temperature of $650^{\circ} \mathrm{C}$ is not desirable. Many of the selected markers are not or less visible with pyrolysis at this temperature. Only marker 25, an unidentified component formed at high temperatures 
in Congo copal, is best detected at $650^{\circ} \mathrm{C}$. This temperature program will be left out in the further discussion.

When comparing the intensity of a peak at the remaining temperature programs, three groups can be discerned. A first group of markers $(2,3,12,13,14,16,19,23$, 27 , indicated with ${ }^{\circ}$ in figure 2) perform well at all temperature programs (UFD, 350, $\left.480,550^{\circ} \mathrm{C}\right)$. Differences between them are minimal. A second group of markers (4, $5,6,7,8,9,15,21,22,26$, indicated with $*$ in figure 2) shows a slight or important trend in favor of low temperatures; these tend to decrease in intensity or disappear at high temperatures. For these molecules, a temperature of $350^{\circ} \mathrm{C}$, is preferable. As expected, UFD performs also very well for these molecules. It seems that those molecules are indeed condensed on the column before higher temperature could destroy them. $480^{\circ} \mathrm{C}$ is a less performing option, but can be esteemed acceptable.

A third group comprises molecules that slightly or explicitly tend to be more present when high temperatures are applied $(1,10,11,17,18,20,24,25$, indicated with + in figure 2). These molecules are best detected with a fixed pyrolysis temperature of $550^{\circ} \mathrm{C}$. A fixed temperature of $480^{\circ} \mathrm{C}$ performs well. Remarkably, UFD does not reach the expectations: for these molecules, UFD shows an overall lower integrated signal than when $480^{\circ} \mathrm{C}$ pyrolysis temperature was applied. Several explanations could be valid and may enforce each other. Possibly, the rise in temperature is so steep that some molecules are still present in the pyrolysis oven and get partially destroyed when the temperature of $660^{\circ} \mathrm{C}$ is reached. However, some limited tests with an adapted UFD, that rise in one minute to only $550^{\circ} \mathrm{C}$, keeping this temperature for another minute, did not perform better. Some molecules may not be formed because their precursors left the oven earlier, or other side reactions may have taken place. The TMAH, abundantly present at the start of the temperature rise, might be volatilized and evacuated together with the first compounds formed, being absent for the compounds formed at higher temperatures.

The analysis of all results shows that both $480^{\circ} \mathrm{C}$ and UFD are valuable pyrolysis temperature programs, returning a significant signal for a whole range of marker molecules. In general, differences between these two options are limited; UFD performs better for heat sensitive compounds that are released at low temperatures (e.g. $350^{\circ} \mathrm{C}$ ), whereas $480^{\circ} \mathrm{C}$ is generally a better choice for compounds formed at high temperatures, best seen at $550^{\circ} \mathrm{C}$. Repeated measures could not reveal significant differences between variances obtained with temperature treatments (ANOVA).

During data analysis, the question rose whether variability depended on the temperature program chosen.

\section{Conclusion}

The experiment illustrates the important influence of thermochemolysis temperature on the integrated signal of several resin markers. The optimal temperature depends on the molecules of interest. However, fixed temperatures of $550^{\circ} \mathrm{C}$ and $650^{\circ} \mathrm{C}$ are not ideal as consensus temperature to detect most markers. $350^{\circ} \mathrm{C}$ could be 
considered, but a fixed temperature of $480^{\circ} \mathrm{C}$ or UFD give best results in detecting the whole series of marker molecules.

\section{References}

1. J. C. Frade, M. I. Ribeiro, J. Graça, and J. Rodrigues, Anal. Bioanal. Chem. 395, 2167 (2009).

2. T. Honda, R. Lu, N. Kitano, Y. Kamiya, and T. Miyakoshi, J. Appl. Polym. Sci. 118, 897 (2010).

3. A. Heginbotham and M. R. Schilling, in East Asian Lacquer: Material Culture, Science and Conservation, edited by S. Rivers, R. Faulkner, and B. Pretzel

(Archetype Publications, London, 2011), pp. 92-106.

4. J. Koller, K. Walch, and U. Baumer, in Japanische Und Europäische Lackarbeiten:

Rezeption, Adaption, Restaurierung / Japanese and European Lacquerware:

Adoption, Adaptation, Conservation, edited by M. Kühlenthal (Bayerisches

Landesamt für Denkmalpflege, Munich, 2000), pp. 537-559.

5. V. Cattersel, L. Decq, C. Indekeu, E. Van Binnebeke, D. Steyaert, W. Fremout, and S. Saverwyns, in Furniture Finishes, Miko Vasques Dias (Stichting Ebenist, Amsterdam, 2015), pp. 56-62.

6. M. Webb, Lacquer: Technology and Conservation: A Comprehensive Guide to the Technology and Conservation of Asian and European Lacquer (ButterworthHeinemann, Oxford, 2000).

7. K. J. van den Berg, J. van der Horst, and J. J. Boon, in Preprints ICOM Committee ICOM for Conservation 12th Triennial Meeting, Lyon, France, 29 Aug-3 September 1999, Vol. II (James \& James, London, Lyon, 1999), pp. 855-861.

8. H. van Keulen, in Furniture Finishes, Miko Vasques Dias (Stichting Ebenist, Amsterdam, 2015), pp. 134-141.

9. J. Romero-Noguera, I. Martín-Sánchez, M. T. Doménech-Carbó, L. Osete-Cortina, M. M. López-Miras, and F. Bolívar-Galiano, Int. Biodeter. Biodegr. 90, 99 (2014).

10. M. Regert, T. Devise, A.-S. Le Hô, and A. Rougeulle, Archaeometry 50, 668 (2008).

11. A.-S. Le Hô, M. Regert, O. Marescot, C. Duhamel, J. Langlois, T. Miyakoshi, C. Genty, and M. Sablier, Anal. Chim. Acta 710, 9 (2012).

12. I. D. van der Werf, K. J. van den Berg, S. Schmitt, and J. J. Boon, Stud. Conserv. 45, 1 (2000).

13. J. Poulin and K. Helwig, Org. Geochem. 44, 37 (2012).

14. K. B. Anderson and R. E. Winans, Anal. Chem. 63, 2901 (1991).

15. K. B. Anderson, R. E. Winans, and R. E. Botto, Org. Geochem. 18, 829 (1992).

16. P. S. Bray and K. B. Anderson, Geochem. T. 9, 3 (2008).

17. M. Havelcová, V. Machovič, M. Linhartová, L. Lapčák, A. Přichystal, and Z. Dvořák, Microchem. J. 128, 153 (2016).

18. K. J. van den Berg, J. Ossebaar, and H. van Keulen, in Proceedings of Art2002,

7th International Conference on Non-Destructive Testing and Microanalysis for the

Diagnostics and Conservation of the Cultural and Environmental Heritage, 2-6 June 2002, Antwerp, Belgium, edited by R. Van Grieken, K. Janssens, L. Van't Dack, and G. Meersman (Antwerp, Belgium, 2002).

19. F. Shadkami and R. Helleur, J. Anal. Appl. Pyrol. 89, 2 (2010).

20. Anne-Solenn Le Hô, Céline Daher, Ludovic Bellot-Gurlet, Yannick

Vandenberghe, Jean Bleton, Myrtho Bonnin, Léa Drieu, Juliette Langlois, Céline 
Paris, Marc-André Paulin, Anne Forray-Carlier, and Anne Jacquin, ICOM-CC Conference Paper (2014).

21. A. Heginbotham, H. Khanjian, R. Rivenc, and M. Schilling, in 15th Triennial Conference New Delhi, 22-26 September 2008: Preprints, ICOM Committee for Conservation (Allied Publishers, New Delhi, 2008), pp. 608-616.

22. J. W. de Leeuw and M. Baas, J. Anal. Appl. Pyrol. 26, 175 (1993).

23. S. Watts and E. R. de la Rie, Stud. Conserv. 47, 257 (2002).

24. D. Scalarone, M. Lazzari, and O. Chiantore, J. Anal. Appl. Pyrol. 115 (2003).

25. K. Sutherland, J. Chromatogr. A 1149, 30 (2007).

26. A. Piccirillo, D. Scalarone, and O. Chiantore, Journal of Analytical and Applied Pyrolysis 74, 33 (2005).

27. J. D. J. van den Berg and J. J. Boon, Journal of Analytical and Applied Pyrolysis 61, 45 (2001).

28. D. Jun-Kai, J. Wei, Z. Tian-Zhi, S. Ming, Y. Xiao-Guang, and F. Chui-Chang, Journal of Analytical and Applied Pyrolysis 42, 1 (1997).

29. I. Pastorova, K. J. van den Berg, J. J. Boon, and J. W. Verhoeven, J. Anal. Appl. Pyrol. 43, 41 (1997).

30. J. M. Challinor, J. Anal. Appl. Pyrol. 61, 3 (2001).

31. C. Riedo, D. Scalarone, and O. Chiantore, Analytical and Bioanalytical Chemistry 401, 1761 (2011).

32. D. Scalarone, M. Lazzari, and O. Chiantore, J. Anal. Appl. Pyrol. 64, 345 (2002).

33. M. T. Doménech-Carbó, J. de la Cruz-Cañizares, L. Osete-Cortina, A. DoménechCarbó, and H. David, Int. J. Mass Spectrom. 284, 81 (2009).

34. S. Prati, S. Smith, and G. Chiavari, Chromatographia 59, 227 (2004).

35. S. Saverwyns, M. Vermeulen, and E. Van Binnebeke, E-Preservation Science 11, 64 (2014).

36. I. D. van der Werf, D. Fico, G. E. De Benedetto, and L. Sabbatini, Microchem. J. 125, 85 (2016).

37. K. B. Anderson and R. E. Botto, Org. Geochem. 20, 1027 (1993).

38. K. B. Anderson, Geochem. Trans. 7, (2006).

39. J. H. Langenheim, Plant Resins: Chemistry, Evolution, Ecology, and Ethnobotany (Timber Press, Portland, Or, 2003).

40. R. J. Stacey, C. R. Cartwright, and C. McEwan, Archaeometry 48, 323 (2006).

41. J. Koller, U. Baumer, E. Schmid, and D. Grosser, in Baroque and Rococo

Lacquers (Bayerischen Landesamtes für Denkmalpflege, Munich, 1997), pp. 379394.

42. F. Piozzi, S. Passannanti, M. Paternostro, and G. Nasini, Phytochemistry 13, 2231 (1974).

43. U. Baumer and P. Dietemann, Anal. Bioanal. Chem. 397, 1363 (2010).

44. J. S. Mills and R. White, Stud. Conserv. 22, 12 (1977).

45. G. Nasini and F. Piozzi, Phytochemistry 20, 514 (1981).

46. G. Steigenberger, The Vigani Cabinet - Analysis of Historical Resinous Materials by Gas Chromatography - Mass Spectrometry and Infrared Spectroscopy - PhD

Dissertation (the Department of Mathematics and Natural Sciences at the Technical University Dresden, 2013).

47. G. Steigenberger and C. Herm, Anal Bioanal Chem 401, 1771 (2011).

48. (n.d.).

49. G. Chiavari, S. Montalbani, and V. Otero, Rapid Commun. Mass Sp. 22, 3711 (2008).

50. K. B. Anderson and W. Bray, Archaeometry 48, 633 (2006). 
